\title{
Effects of STN-DBS on Depression and Cognitive Status Dementia in Patients with Parkinson's Disease
}

\author{
Vahid Ghadri ${ }^{1}$, Omid Rezaei ${ }^{2}$, Mohammad Ebrahimzadeh Mousavi ${ }^{3}$, \\ Mansour Parvaresh ${ }^{4}$, Sadegh Ghadri ${ }^{5}$ \\ ${ }^{1}$ Phd Candidate Psychology, Azad University Science and Research Branch, Theran, Iran. \\ ${ }^{2}$ M.D. Associate Professor of Psychiatry, Psychosis Research Center, Psychiatry Department, \\ University of Social Welfare and Rehabilitation Sciences, Tehran, Iran. \\ ${ }^{3}$ M.S in Clinical Psychology, Department of Clinical Psychology, Faculty of Behavioral Science, \\ University of Social Welfare and Rehabilitation Sciences, Tehran, Iran \\ ${ }^{4}$ M.D. Associate Professor of Neurosurgery Rasoul-e-Akram Hospital, Iran University of Medical \\ Sciences (IUMS),Tehran, Iran \\ ${ }^{5}$ M.D. Neurosurgeon. University of Medical Science Iran, Tehran, Iran
}

Corresponding Author:

Ghadri_teach@yahoo.com,Tel: +98-9125481691

\begin{abstract}
Non-motor symptoms such as depression and in later phases dementia are common features of Parkinson's disease. For the first time in Iran, the present study aims to examine the effects of deep brain stimulation of the subthalamic nucleys (STN-DBS) on cognition and mood through neuropsychological assessment of patients with Parkinson's disease. Stimulation of the subthalamic has no negative effect on the short-term cognitive status of patients with Parkinson's disease, and improves depression. Precise psychological evaluation helps better recognition of the effects of this kind of surgery, which may be useful in providing quality services for those who will be candidates for this surgery in the future.
\end{abstract}

Keywords : Parkinson's disease; DBS; STN; neuropsychological; depression; cognition

\section{Introduction}

Parkinson's disease (PD) is a neurodegenerative disorder caused by degeneration of dopamine producing neurons in the substantia nigra pars compacta of the basal ganglia. PD symptoms can be divided into two main categories. The first category includes motor symptoms such as bradykinesia, rigidity and tremor [1], and the second consists of non-motor symptoms such as, cognitive impairment, and psychiatric problems including depression, [2], [3].Treatments for motor problems of patients with PD include pharmacotherapy focusing on dopamine replacing agents and surgical treatments, especially Deep Brain Stimulation (DBS). DBS is a neurosurgical procedure in which electrodes are chronically implanted in the target area in the brain, most commonly the subthalamic nucleus (STN). Effectiveness of STN-DBS in treating the motor symptoms and medication-induced motor complications of PD and improving the quality of life of the patients is well-proven in controlled clinical trials, [4], [5]. One of the important questions is whether STN-DBS has positive effects on non-motor symptoms of PD. The aim of our study was to examine the effect of STN-DBS on depression and cognition in PD.

\section{Methodology}

Design: This study used a repeated measures design, with pretest/posttest in which "the change in mental status" of each patient was assessed before and after the STN-DBS, and "depression severity" was assessed on five occasions. Sample: The sample included 8 patients with PD attending the Rasool Akram Hospital, Tehran, Iran in July 2015 who were 
candidates for STN-DBS surgery according to the opinion of their physician (a movement disorder specialist). All were candidates for STN-DBS surgery and met the following criteria: at least 5 years past diagnosis, multiple debilitating on-off cycles (with or without dyskinesia), symptoms responding well to dopaminergic medications, having received different treatments and taking various PD medications without responding to them, and severe symptoms to the point of interfering with patient's everyday life [6] .Six participants were men and 2 were women. The mean age of participants was 51 years, and the average time past diagnosis was 9.5 years. No patient had a family history of PD. Table 1 shows the medication the patients were taking before and after STN-DBS surgery. All participants provided informed consent. Confidentiality of the personal information was ensured.

\subsection{Measurement Instruments}

The Beck Depression Inventory-II (BDI-II): This was developed by Beck, Steer, and Brown to assess severity of depression according to the depression criteria of the Diagnostic and Statistical Manual of Mental Disorders, 4th Edition (DSM-IV) and cognitive theory. The BDI-II has 21 items which cover the affective, cognitive and behavioural symptoms of depression. Scores range from 0 to 63 , with higher scores indicating more severe selfreported depression [7]. reported a reliability estimate of .913 for the BDI-II for an Iranian sample.

The Short Portable Mental Status Questionnaire (SPMSQ): It was developed by Pefeiffer [8]. It has 10 items, and is verbally administered. In an internal consistency examination in an Iranian sample [9] , found a Cronbach's alpha of .94 which indicated internal consistency of the questionnaire in discriminating groups with and without dementia. The SPMSQ items cover orientation in place and time. Scores range from 0 to 8 or more errors, with higher scores indicating more severe cognitive impairment. One more error is allowed in the scoring if a patient has had a grade school education or less. One less error is allowed if the patient has had education beyond the high school level.

\subsection{Procedure}

After participants were selected before surgery, the instruments were administered to them, and their answers were recorded. Then, they were placed on the list of surgery candidates. First, the stereotactic frame was fixed for them. In the next step, before putting the patients into the MRI machine, they were put individually into general anesthesia so that the interference of patients' tremors with the work of the MRI machine could be prevented [10]. After determining the anatomical location of subthalamic nucleus in the brain, patients underwent a surgery for implanting the electrodes and the impulse generating devicefor DBS [11]. The BDI-II data were collected on five occasions: before surgery, 2 days after surgery (DBS generator was off), 5 weeks after surgery (DBS was on, and treatment components were adjusted), 11 weeks after surgery (DBS was on, and treatment components were adjusted), and 14 weeks after surgery (DBS was on, and treatment components were adjusted). The SPMSQ data were collected on 2 occasions: pretest (before surgery) and at posttest (14 weeks after surgery).

\subsection{Data analysis}

The study data were analyzed using SPSS software v.21. Descriptive statistics were used to summarize the demographic characteristics of patients. Paired sample t-test, analysis 
of variance, and repeated measures ANOVA were used for continuous and categorical variables. 2 -sided $\mathrm{p}$-value of $<0.05$ was regarded as statistically significant.

\section{Results}

Table 1 shows the names and doses of medications used by each patient before and after the surgery.

Table 1. Medications taken by the patients before and after the surgery.

Name and dosage (mg in 24 hours)

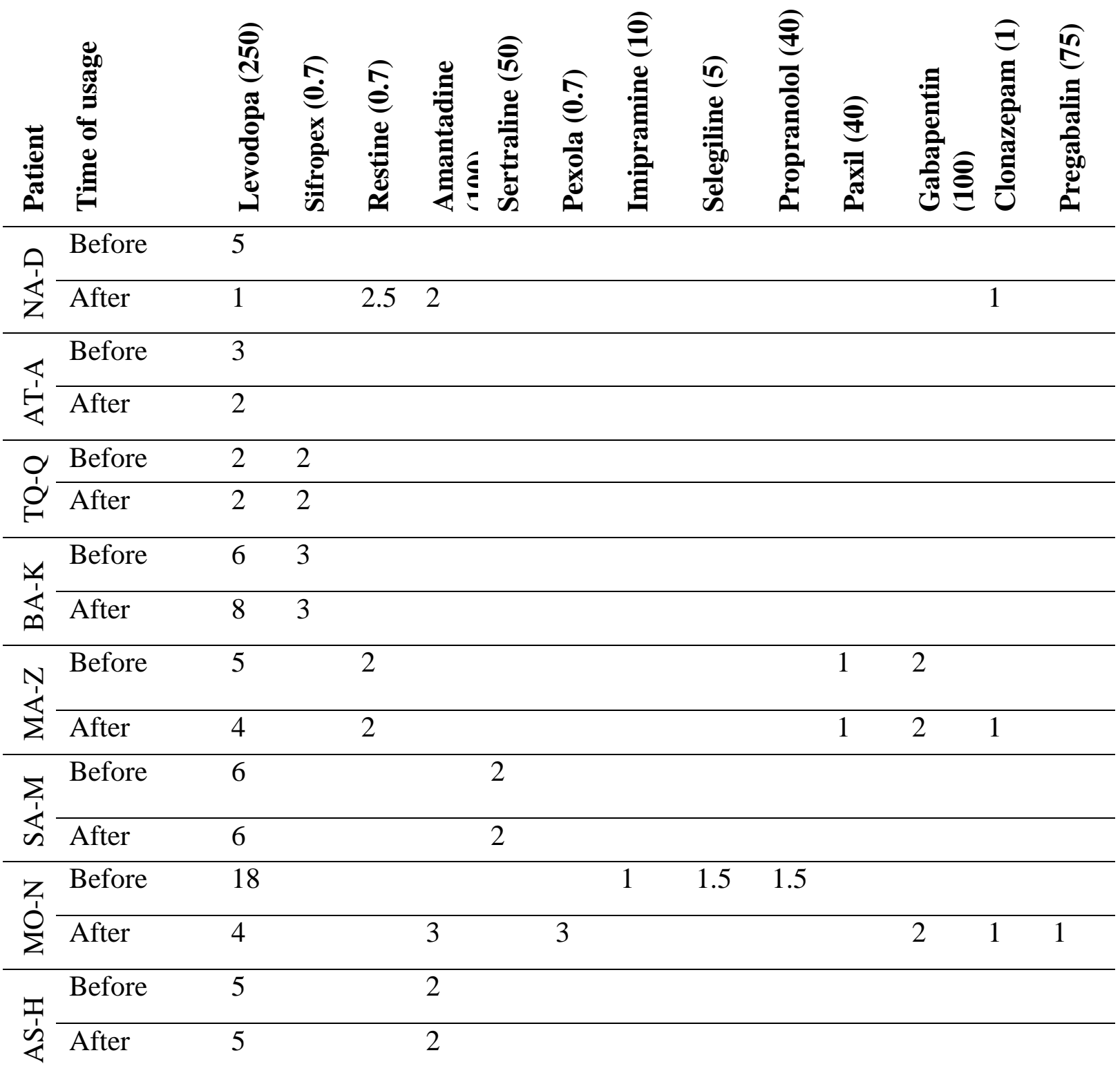




\begin{tabular}{|c|c|c|c|c|c|}
\hline \multicolumn{6}{|c|}{ Table2. Descriptive findings for the study variables. } \\
\hline & $\begin{array}{l}\text { Lowest } \\
\text { score }\end{array}$ & $\begin{array}{l}\text { Highest } \\
\text { score }\end{array}$ & Mean & SD & Number \\
\hline $\begin{array}{l}\text { Dementia } \\
\text { scores at } \\
\text { pretest } \\
\end{array}$ & 7 & 9 & 8.37 & .74 & 8 \\
\hline $\begin{array}{l}\text { Dementia } \\
\text { scores at } \\
\text { posttest }\end{array}$ & 7 & 9 & 8.37 & .92 & 8 \\
\hline $\begin{array}{l}\text { Depression } \\
\text { scores at } \\
\text { pretest }\end{array}$ & 13 & 34 & 20.37 & 6.41 & 8 \\
\hline $\begin{array}{l}\text { Depression } \\
\text { scores } \\
\text { obtained } 2 \\
\text { days after the } \\
\text { surgery }\end{array}$ & 6 & 28 & 16.25 & 7.75 & 8 \\
\hline $\begin{array}{l}\text { Depression } \\
\text { scores } \\
\text { obtained } 5 \\
\text { weeks after } \\
\text { the surgery }\end{array}$ & 4 & 26 & 12.62 & 6.13 & 8 \\
\hline $\begin{array}{l}\text { Depression } \\
\text { scores } \\
\text { obtained } 11 \\
\text { weeks after } \\
\text { the surgery }\end{array}$ & 7 & 28 & 14.50 & 7.07 & 8 \\
\hline $\begin{array}{l}\text { Depression } \\
\text { scores } \\
\text { obtained } 14 \\
\text { weeks after } \\
\text { the surgery }\end{array}$ & 8 & 26 & 16.50 & 6.32 & 8 \\
\hline
\end{tabular}

According to Table 3, In order to examine the effects of STN-DBS on depression, depression scores were assessed on 5 occasions, and it was found that they were higher at the pretest compared to the 4 other posttest occasions. Among the posttest scores, the scores from the occasion 5 were the highest.

The level of depression was significantly different between the 5 occasions $\left(F_{(4,28)}=3.45\right.$, $\mathrm{p}<0.05)$.

The Tukey's post hoc test was used to identify the pair of occasions with a sginficant difference, and to determine whether the pre-surgery occasion was significantly different from each of the 5 post-surgery occasions; the results are presented in Table 3 . 


\begin{tabular}{|c|c|c|c|c|}
\hline $\begin{array}{l}\text { Source of } \\
\text { change }\end{array}$ & Assessment & $\begin{array}{l}\text { Mean of } \\
\text { differences }\end{array}$ & SD & Sig. \\
\hline \multirow[t]{4}{*}{ Pretest } & $\begin{array}{l}2 \text { days after the } \\
\text { surgery }\end{array}$ & 4.25 & 2.51 & 0.134 \\
\hline & $\begin{array}{l}5 \text { weeks after the } \\
\text { surgery }\end{array}$ & 7.75 & 1.66 & 0.002 \\
\hline & $\begin{array}{l}11 \text { weeks after } \\
\text { the surgery }\end{array}$ & & 1.17 & 0.002 \\
\hline & $\begin{array}{l}14 \text { weeks after } \\
\text { the surgery }\end{array}$ & 3.87 & 2.88 & 0.221 \\
\hline \multirow[t]{3}{*}{$\begin{array}{l}2 \text { days after the } \\
\text { surgery }\end{array}$} & $\begin{array}{l}5 \text { weeks after the } \\
\text { surgery }\end{array}$ & 3.50 & 2.10 & 0.139 \\
\hline & $\begin{array}{l}11 \text { weeks after } \\
\text { the surgery }\end{array}$ & & 2.48 & 0.533 \\
\hline & $\begin{array}{l}14 \text { weeks after } \\
\text { the surgery }\end{array}$ & -0.37 & 2.57 & 0.888 \\
\hline \multirow[t]{2}{*}{$\begin{array}{l}5 \text { weeks after } \\
\text { the surgery }\end{array}$} & $\begin{array}{l}11 \text { weeks after } \\
\text { the surgery }\end{array}$ & -1.87 & 1.66 & 0.297 \\
\hline & $\begin{array}{l}14 \text { weeks after } \\
\text { the surgery }\end{array}$ & -3.87 & 2.01 & 0.096 \\
\hline $\begin{array}{l}11 \text { weeks after } \\
\text { the surgery }\end{array}$ & $\begin{array}{l}14 \text { weeks after } \\
\text { the surgery }\end{array}$ & -2.00 & 2.28 & 0.409 \\
\hline \multicolumn{5}{|c|}{$\begin{array}{l}\text { According to Table } 3 \text {, there was a significant difference between depression scores at } \\
\text { pretest and those at the two post-surgery occasions, i.e. weeks } 5 \text { and } 11(\mathrm{p}<0.01) \text {, but there } \\
\text { was no significant difference between depression scores at pretest and those at day } 2 \text { and } \\
\text { week } 14 \text { after the surgery ( }>0.05) \text {. In other words, the level of depression in the patients was } \\
\text { significantly higher before the surgery compared to that at weeks } 5 \text { and } 11 \text { after the surgery, } \\
\text { but it was not significantly different from the level of depression at day } 2 \text { and week } 14 \text { after } \\
\text { the surgery (Diagram 1). } \\
\text { Examination of the effects of STN-DBS on the SPMSQ for each patient indicated no } \\
\text { significant change in cognitive status after the surgery. The paired sample t-test was used to } \\
\text { compare the pretest and posttest scores. The results of the paired sample t-test showed no } \\
\text { significant difference between the pretest and posttest scores on the SPMSQ scale (p>0.05).In } \\
\text { other words, STN-DBS had no negative effect on cognitive status. }\end{array}$} \\
\hline
\end{tabular}

\section{Discussion}

The patient's level of depression was significantly different among the 5 assessment occasions. It was significantly higher before the surgery than it was at weeks 5 and 11 after the surgery, but was not significantly different between pre-surgery assessment and day 2 and week 14 after the surgery. Thus, the level of depression was lowest at weeks 5 and 11 after the surgery $(\mathrm{p}>0.01)$. Therefore, STN-DBS reduces depression in patients with PD. By contrast, STN-DBS did not alter the patients' cognitive status measured on SPMSQ. Depression could be seen as a non-motor manifestation of PD, but some issues should be noted: First of all, it has been observed that tapering off or quitting dopaminergic medications 
lead to depression or worsen depression symptoms, and the need for taking dopaminergic medications is reduced for patients who undergo DBS surgery. Secondly, some believe that DBS has positive effects on the non-motor manifestations of PD. For example, depression occurs in patients with PD with a yearly incidence rate of $2 \%$. In patients who have undergone DBS, there are more accurate estimates of the level of depression: $2 \%$ to $25 \%$ [12]. Many studies have been performed on the prevalence of depression among patients with PD before and after STN-DBS, but the focus of the present study was on the severity of depression before and after surgery (In fact, depressed PD patients were not included in our study). In a study by Calabresi [13], reduction in the doses of dopaminergic medications taken by PD patients was shown to have a role in patients' depression or worsening of their depression symptoms after the surgery; for some of the patients in our study, the dosage and number of dopaminergic medications was not reduced after the surgery. Castelli, et al [14]measured the severity of depression 2 weeks before surgery and again 15 weeks after surgery, and found a slight improvement, but in the preset study, depression level was significantly different from the pre-surgery assessment only at weeks 5 and 11 after the surgery. In overall, the results of the present study indicated that, notwithstanding a slight increase in the severity of depression in the first two weeks after the surgery, there were significant improvements at weeks 5 and 11. In a study by Witt and Daniel [15], "surgical stress and nature of the underlying disease," were considered as two factors that could lead to depression or worsen depression symptoms in the first 2 weeks after surgery. Depression severity was reduced to some extent at week 14 after the surgery, but it was not statistically significant. No significant difference was observed in the scores on the SPMSQ before and after the surgery. The results of paired sample t-test indicated that the scores on the SPMSQ were not different before and after the surgery. In other words, the surgery had no negative effect on dementia. According to our examinations, none of the patients had dementia or psychological disorders, before or after the surgery. Voon et al [16] showed that stimulation of the subthalamic nucleus is more likely to lead to dementia or worsen dementia symptoms than stimulation of the internal globus pallidus (GPi), however, this has not been proven in any reliable study. In contrast, the results of the present study indicated that, although STNDBS could not reduce dementia scores ( $p>0.05$ ), it had no negative impact on dementia. Voon et al [16], showed that dementia in patients with PD could be due to high frequency stimulations or damage to the subthalamic nucleus during electrode implantation or both, and that the role of these factors should be separately assessed, but in the present study, it was found that none of these factors could lead to dementia or make it worse.

On the other hand, if dementia is in an advanced stage before the surgery or reach an advanced stage after the surgery, the patient will not benefit from the motor improvements resulted from STN-DBS, because impairment in the quality of life of these patients is so severe that motor improvements are not very helpful for them [16]. In an eight-year long longitudinal study, the incidence of dementia after surgery was reported to be $38 \%$ [17]. The present study is not completely consistent with the previous ones, and this may be due to the fact that the current study was conducted over 5 months, therefore, given the gradual course of dementia, we suggest future studies use standard designs with longer follow-ups. The use of biological markers and Magnetic Resonance Imaging (MRI) of the brain anatomy can help early diagnosis of dementia in patients with PD. Therefore, it can be argued that PD is widely related to mild cognitive impairments and dementia [18]. Over the past 50 years, Levodopa has been the first-line therapy for PD [19]. In the present study, examination of the 
medications taken by the patients before and after the surgery indicated that they were still dependent on some mediations, such as Levodopa, but there was no significant difference between their medication use before and after the surgery. As was observed in the subjects of the current study, due to the effectiveness of STN-DBS in the reduction of patients' motor symptoms, the amount of medications taken by the patients is reduced after the STN-DBS. However, longitudinal study designs, larger statistical populations, and longer follow-ups are needed to examine the effects of other medications on the neuropsychological condition of patients with PD, because different medications are prescribed for the patients, and not many studies have focused on medications other than Levodopa.

\section{Conclusion}

In overall, the study results indicate that STN-DBS can be considered as a useful method for treating depression, therefore improving the everyday functioning and quality of life of patients with PD, and although it is not effective in reducing dementia symptoms, it has no negative effect on dementia. Therefore we can argue that STN-DBS that is regarded as a standard treatment method for motor impartments in patients with PD, should be considered as an "effective surgery for neuropsychological disorders."

\section{Suggestions for future research}

The negative effects of cognitive impairment and depression on the quality of life of patients with PD [20] are sometimes so severe that the patients do not benefit form improvement in their motor impairments with STN-DBS. Therefore, regular psychical and psychological care should be provided for the patients after the surgery. We also suggest future studies to examine the behavioral and mental responses of patients against different frequencies in order to find the lowest and highest allowed frequencies useful in improving the patients' health. Surgical teams for functional surgeries must include an experienced neuropsychologist, because patients who undergo STN-DBS, in addition to having to pay the high costs of treatment, are prone to some complications following the surgery. Another important issue concerns quitting dopaminergic medications after STN-DBS. Stopping or reducing dopaminergic medications can lead to or worsen depression in PD. Ttherefore we suggest that future controlled clinical trials should attempt to differentiate between changes in depression in association with STN-DBS and depression relating to stopping or reducting dopaminergic medications after STN-DBS.

\section{References}

[1] Giladi N, Mcdermott MP, Fahn S, Przedborski S, Jankovic J, et al. Parkinson Study Group. Freezing of gait in PD Prospective assessment in the DATATOP cohort. Neurology 2001:26;56:1712-21.

[2] Hely MA, Reid WG, Adena MA, Halliday GM, Morris JG. The Sydney multicenter study of Parkinson's disease: the inevitability of dementia at 20 years. Movement disorders 2008;23:837-44.

[3] Moazzami, D. An introduction to neuropsychology. Tehran Samt 2013, p.74-77.

[4] Deuschl G, Schade Brittinger C, Krack P, Volkmann J, Schafer H, et al. A randomized trial of deep-brain stimulation for Parkinson's disease. New England Journal of Medicine 2006;31;355:896-908. 
[5] Williams A, Gill S, Varma T, Jenkinson C, Quinn N, et al. Deep brain stimulation plus best medical therapy versus best medical therapy alone for advanced Parkinson's disease (PD SURG trial): a randomised, open-label trial. Lancet Neurol (NLM) 2010;30;9:581-91.

[6] Okun MS, Zeilman PR. Parkinson's disease: Guide to deep brain stimulation therapy. National Parkinson Foundation (NPF) 2014;23:837

[7] Mohammadkhani P, Dobson KS, Amiri M, Hosseini Ghafari F. Psychometric properties of the Brief Symptom Inventory in a sample of recovered Iranian depressed patients. International Journal of Clinical and Health Psychology (IJCHP) 2010;10:3.

[8] Pfeiffer E. A short portable mental status questionnaire for the assessment of organic brain deficit in elderly patients. Journal of the American Geriatrics Society(AGS) 1975;1:433-41.

[9] Salehi H, Nezakatolhoseini M, Azadian A. Attention Deficit During Dual-Task Performance in Alzheimer's Disease Patients. Iranian Journal Ageing(IGA) 2014;15:88-96.

[10] Sa'atian, M., \& Parvaresh, M. Determining the appropriate place of DBS in patients with dystonia. (Unpublished doctoral dissertation). Iran University of Medical Sciences(IUMS), Tehran, Iran 2013;28:18.

[11] Tabibkhooei A, Parvaresh M. Determining the appropriate place of STN for DBS in patients with Parkinson's disease. (Unpublished doctoral dissertation) Iran University of Medical Sciences, Tehran, Iran 2013;4:217.

[12] Miyasaki JM, Shannon K, Voon V, Ravina B, Kleiner fisman G, et al. Practice Parameter Evaluation and treatment of depression, psychosis, and dementia in Parkinson disease (an evidence-based review) Report of the Quality Standards Subcommittee of the American Academy of Neurology (AAN) Neurology 2006;11;66:996-1002.

[13] Calabresi PA, Giovannoni G, Confavreux C, Galetta SL, Havrdova E, et al. The incidence and significance of anti-natalizumab antibodies Results from AFFIRM and SENTINEL. Neurology 2007;2;69:1391-403.

[14] Castelli L, Perozzo P, Zibetti M, Crivelli B, Morabito U, Lanotte M, et al. Chronic deep brain stimulation of the subthalamic nucleus for Parkinson's disease: effects on cognition, mood, anxiety and personality traits. European neurology 2006;55:136-44.

[15] Witt K, Daniels C, Reiff J, Krack P, Volkmann J, et al. Neuropsychological and psychiatric changes after deep brain stimulation for Parkinson's disease a randomised, multicentre study. The Lancet Neurology 2008;31;7:605-14.

[16] Voon V, Moro E, Saint-Cyr JA, Lozano AM, Lang AE. Psychiatric Symptoms Following Surgery for Parkinson's Disease with an Emphasis. Behavioral Neurology of Movement Disorders 2005;96:130.

[17] Hughes TA, Ross HF, Musa S, Bhattacherjee S, Nathan RN, Mindham RH, et al. A 10-year study of the incidence of and factors predicting dementia in Parkinson's disease. Neurology 2000;25;54:1596-603.

[18] Morales DA, Vives-Gilabert Y, Gómez-Ansón B, Bengoetxea E, Larrañaga P, Bielza C, et al. Predicting dementia development in Parkinson's disease using Bayesian network classifiers. Psychiatry Research: NeuroImaging 2013;30;213:92-8.

[19] Mehanna R, Lai EC. Deep brain stimulation in Parkinson's disease. Translational neurodegeneration 2013;18;2:22.

[20] Schrag A, Jahanshahi M, Quinn N. What contributes to quality of life in patients with Parkinson9s disease?. Journal of Neurology, Neurosurgery \& Psychiatry 2000;1;69:308- 